\title{
Long term aging treatment impact on ultralow iron Alloy 625
}

\author{
intergranular corrosion property
}

\author{
Zhi-yuan $\mathrm{Zhu}^{1)^{*}}$, Yi Sui ${ }^{1)}$, An-lun Dai ${ }^{1)}$, Yuan-fei $\mathrm{Cai}^{1}{ }^{1}$, Ling-li Xu ${ }^{1)}$, Ze-xin Wang ${ }^{1)}$, \\ Hong-mei Chen ${ }^{1)}$, Xing-ming Shao ${ }^{2)}$, Wei Liu ${ }^{2)}$
}

1) School of Materials Science and Engineering Jiangsu University of Science and Technology, Zhenjiang Jiangsu 212003, China

2)Jiangsu Xinhua Alloy Electric Co.,LTD., Xinghua Jiangsu 225722, China

Abstract: This paper investigates the evolution of microstructures and precipitations of an ultra-low iron alloy 625 subjected to long term aging treatment by scanning electron microscope (SEM) and X-ray diffraction(XRD). Use ASTM G28A acid $\mathrm{Fe}_{3}\left(\mathrm{SO}_{4}\right)_{2}$ erosion to represent intergranular corrosion weightlessness and corrosive morphology. The result shows that alloy at $750^{\circ} \mathrm{C}$ by aging treatment for $40 \mathrm{~h}$, precipitated $\gamma^{\prime \prime}$ phase in the grain boundary. In high density area of $\gamma^{\prime \prime}$ phase, occurs $\gamma^{\prime \prime}$ phase to $\delta$ phase degeneration transformation by aging treatment for $200 \mathrm{~h}$ and the needle-like $\delta$ phase becomes more with time prolonged. And $\gamma$ " phase degenerated to $\delta$ phase completely until treated for $1000 \mathrm{~h}$. The sample which has aging treatment tends to have intergranular corrosion and mainly because alloy element spreading leads to dilution area and grain boundary precipitated phase, plus interlaced $\delta$ phase's dissolving, which makes sample grain particle fall off and this results in apparent weightlessness. The weightlessness rate(WLR) is related with precipitated volume score. With aging sensitization time change, can be described by Johnson-Mehl-Avrami equation, i.e.:

$W L R=44.32\left[1-\exp \left(-\frac{t}{10.99}\right)\right]+44.62\left[1-\exp \left(-\frac{t}{327.8}\right)\right]+1.267(\mathrm{~mm} / a)$.

Key words: Alloy 625; aging sensitization treatment; intergranular corrosion; ASTM G28A methods

\section{Introduction}

Nickle base alloy has good strengthens, ductility and toughness, welding and anticorrosive property. It is widely used in oceaneering welded structure, petrochemical engineering, energy and power evaporator $[1,2]$ and its reinforcement theory is widely studied and reported, so we are familiar with it [3]. Among this, Alloy 625 is considered as the ideal material of main parts for the $4^{\text {th }}$ generation of nuclear station [4,5]. Alloy's aging and creep property is an important parameter to ensure nuclear station's safety operation. Alloy 625 can precipitate $\mathrm{Ni}_{3} \mathrm{Nb}$ and carbide [7-9] in high temperature by long term. $\gamma^{\prime \prime}-\mathrm{Ni} 3 \mathrm{Nb}$ precipitation and prolonged heat keeping can degenerate to needlelike $\delta-\mathrm{Ni}_{3} \mathrm{Nb}$ [8]. In the evolution, alloy is hardened [9], ductility and toughness is decreased [7], element spread and separate out, Alloy 625 is sensitized. In oxidant transmitter, $\mathrm{Ni}_{3} \mathrm{Nb}$ with low $\mathrm{Cr}$ value as anode is corroded [10]. In addition, carbide and

*Corresponding author: Zhi-yuan Zhu E-mail: salanganezhu@163.com 
dilution area cause intergranular corrosion tendency [11-14]. Pay attention to alloy's mechanics and anti-corrosion property's change during aging process can increase structure's stability, which is an effective way to prolong high-temperature components' life. However, in the long term of aging and sensitization process, precipitation phase generation and conversion impact on alloy's anti-corrosion property is rarely investigated.

Table 1 The Main Phases Occurring in long-term aging Nickel-based superalloy[15]

\begin{tabular}{|c|c|c|}
\hline Phase & Structure & Typical Composition \\
\hline$\gamma^{\prime \prime}$ & body-centered tetragonal & $\mathrm{Ni}_{3}\left(\mathrm{Nb}_{>0.5}, \mathrm{Ti}_{<0.5}, \mathrm{Al}_{<0.5}, \mathrm{Mo}_{<0.5}\right)$ \\
\hline$\delta$ & orthorhombic & $\mathrm{Ni}_{3} \mathrm{Nb}$ \\
\hline $\mathrm{MC}$ & cubic & $(\mathrm{Nb}, \mathrm{Ti}) \mathrm{C}$ \\
\hline $\mathrm{M}_{6} \mathrm{C}$ & cubic & $\left(\mathrm{Cr}_{>0.2}, \mathrm{Mo}_{>0.2}, \mathrm{Fe}\right) \mathrm{C}$ \\
\hline $\mathrm{M}_{23} \mathrm{C}_{6}$ & cubic & $\left(\mathrm{Cr}_{>0.8}, \mathrm{Fe}, \mathrm{Mo}\right) \mathrm{C}$ \\
\hline Laves & $\operatorname{MgZn} n_{2}$-Types $\left(\mathrm{AB}_{2}\right)$ & $\mathrm{TiFe}_{2}, \mathrm{NbFe}_{2}, \mathrm{MoFe}_{2}$, etc. \\
\hline$\mu$ & Hexagonal $\left(\mathrm{B}_{7} \mathrm{~A}_{6}\right)$ & $\mathrm{Fe}_{7} \mathrm{Mo}_{6}, \mathrm{Fe}_{7} \mathrm{Nb}_{6}, \mathrm{Fe}_{7} \mathrm{Mo}_{6}$, etc \\
\hline$\sigma$ & Tetragonal(BA) & $(\mathrm{Cr}, \mathrm{Mo})_{\mathrm{x}}(\mathrm{Ni}, \mathrm{Fe})_{\mathrm{y}}: \mathrm{FeCr}, \mathrm{MoFe}, \mathrm{NbFe}$, etc. \\
\hline
\end{tabular}

In present study, Alloy 625 (ASTM B446) contains 2-5\%wt Fe, which can solution strengthen basal body to increase strength. However, there is Topological Close-Packed Phase in long term aging, such as Laves phase, $\mu$ phase and $\sigma$ phase $[8,16]$. As shows in Table 1, it is board-like or needle-like shape, which decreases alloy's breakage strength and ductility $[8,17]$. Besides, Si facilitates harmful phase [15]. Excessive use of it in nuclear material will has hide safety risk.

The Alloy 625 used here optimizes ASTM B446's element composition, controls Fe lower than $0.05 \%$ wt. in addition, $\mathrm{Si}, \mathrm{P}$ and $\mathrm{S}$ percentages are seriously controlled to prevent rich-iron harmful phase occurring and make a new type of ultralow iron Alloy 625. This paper makes characterization analysis of precipitation phase transformation and intergranular anti-corrosion property of ultralow iron Alloy 625 in long term aging sensitization process.

\section{Experiment material and method}

Compared with ASTM B446, Alloy 625 has strict control of Fe percentage to avoid Fe causing property becoming deterioration in the aging process. The experiment used alloy is provided by Jiangsu XinHua Alloy Electric CO., LTD.. It is made by the process of vacuum melting and electroslag re-melting duplex, and forged in 1120$1030^{\circ} \mathrm{C}$, then is cutted by electro-spark wire. After this, it is solid solution treated in $1140^{\circ} \mathrm{C}$ for $4.5 \mathrm{~h}$, water cooling, stabilizing treated in $1000{ }^{\circ} \mathrm{C}$ for $6.5 \mathrm{~h}$, air cooling. Its component shows in Table 2:

Table 2 Chemical Composition of Alloy 625

\begin{tabular}{ccccccccccccc}
\hline${ }_{\text {wt}} \%$ & $\mathrm{C}$ & $\mathrm{Cr}$ & $\mathrm{Mo}$ & $\mathrm{Co}$ & $\mathrm{Nb}+\mathrm{Ta}$ & $\mathrm{Fe}$ & $\mathrm{Al}$ & $\mathrm{Ti}$ & $\mathrm{Si}$ & $\mathrm{P}$ & $\mathrm{S}$ & $\mathrm{Ni}$ \\
\hline ASTM B446 & $<0.1$ & $20-23$ & $8-10$ & $<1$ & $3.15-4.15$ & $<5$ & $<0.4$ & $<0.4$ & $<0.5$ & $<0.02$ & $<0.02$ & $\mathrm{BAL}$ \\
Alloy 625 & 0.05 & 22.4 & 9.5 & 0.03 & 3.66 & 0.01 & 0.24 & 0.23 & 0.04 & 0.002 & 0.001 & 63.1 \\
\hline
\end{tabular}


Aging treatment is in $750^{\circ} \mathrm{C}$, heat preservation for $1000 \mathrm{~h}$, then the alloy is grinded and polished. Adopt D8 Advance A25X to do XRD experiment. The polished sample is corroded in 2vol.\% bromine methyl alcohol and use Zeiss MERLIN Compact field to send SEM for observing appearance. The sample size for intergranular corrosion sensibility test is $50 \times 24 \times 5( \pm 0.3) \mathrm{mm}$. Re-measure the size after surface refined grinding. As per ASTM G28A-02 Standard Test Methods of Detecting Susceptibility to Intergranular Corrosion in Wrought, Nickel-Rich, Chromium-Bearing Alloy Method A-Ferric Sulfate-Sulfuric Acid Test[18] requirement, it is corroded in $\mathrm{H}_{2} \mathrm{SO}_{4}+\mathrm{Fe}_{2}\left(\mathrm{SO}_{4}\right)_{3}$ solution for $120 \mathrm{~h}$, record the weightlessness data, and draw curve. Then observe corrosive surface by SEM after experiment. Cut sample and is packed and inlayed by epoxy resin, the cross profile of sample is eroded in $10 \%$ oxalic acid solution after grinding and polishing until the surface structure is rightly exposed. Spray metal on surface before test for better imaging quality. Compare and analyze structure impact on corrosion process.

\section{Experiment result and analysis}

\section{1 Alloy 625 structure in aging process}
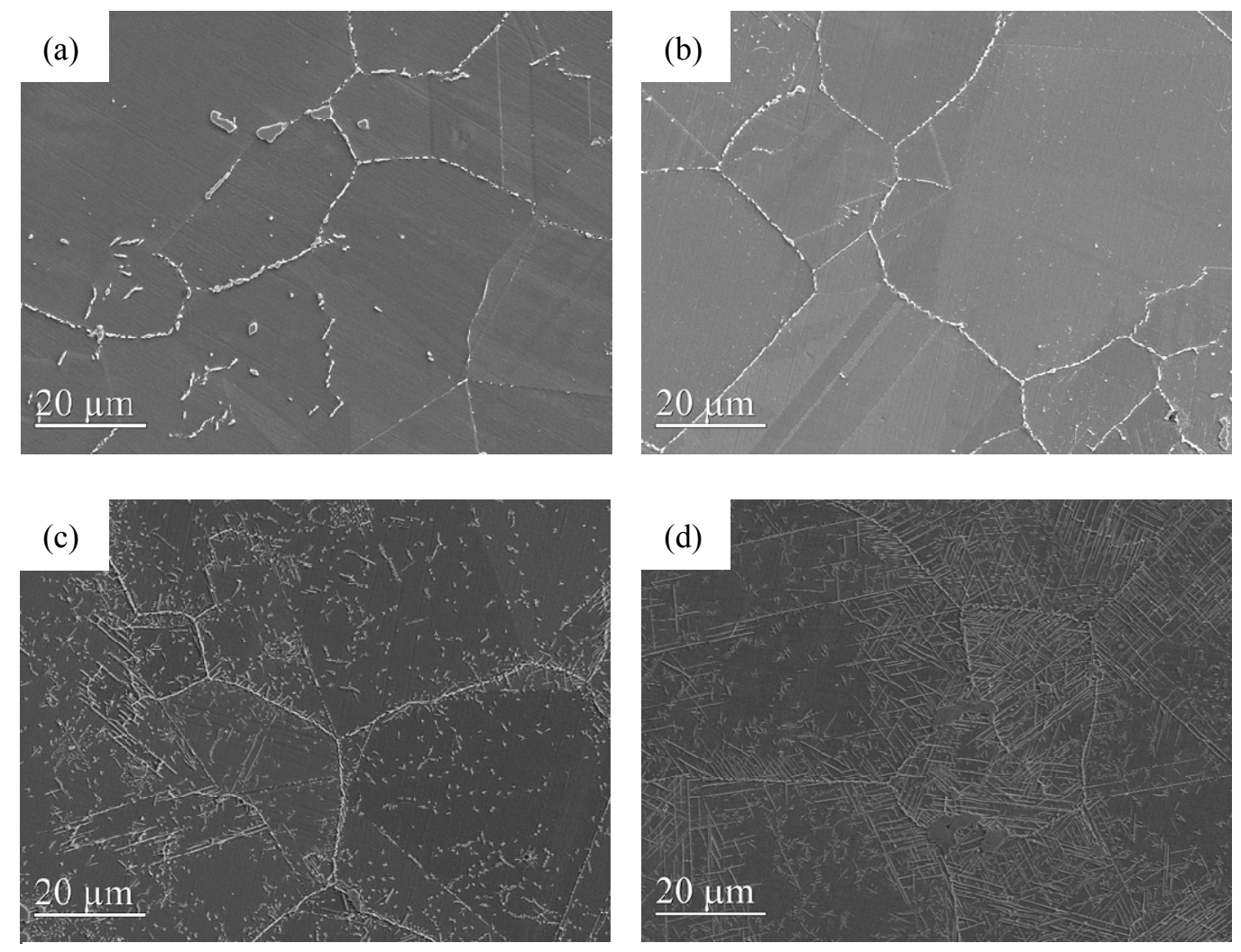

Fig.1 Microstructure of different aging sensitization alloy by means of SEM

(a) $0 \mathrm{~h}$ aging (b)40h aging (c)200h aging (d)1000h aging

As shown in Fig 1, Alloy 625 structure changes with time by aging treatment in $750^{\circ} \mathrm{C}$. It can be discovered in Fig.1 (a) which hasn't aging treatment, carbide is separated out in grain boundary and twin-boundary. It is wee and discontinuous graininess. It is separated out in stabilizing treatment process. In aging process, these 
carbide particles prevent grain boundary migration. While provides nucleation locus for precipitated phase [6].

Observing aging treatment sample can see that small quantity and wee $\gamma^{\prime \prime}$ phase is separated out in grain boundary and twin-boundary after 40h aging treatment with the help of defected nucleation as shown in Fig 1 (b). With prolonged aging, sub-stability $\gamma^{\prime \prime}$ phase's density is increasing and coarsening, also at the same converts to stable $\delta$ phase. As shown in Fig 1 (c) by treated 200h, there is $\delta$ phase in grain boundary with needle-like shape and grows to intergranular from intergranular. Inside grain, $\gamma^{\prime \prime}$ phase is separated out constantly with coarsening. As shown in Fig 1 (d) by treated 1000h, $\delta$ phase is separated out continuously with bigger volume. Inside grain, short and needlelike shape precipitated phase becomes coarse $\gamma^{\prime \prime}$ phase. In addition, appears big particle of carbide in triple line boundary by aging treatment for $1000 \mathrm{~h}$ and EDS shows $(\mathrm{Nb}, \mathrm{Ti}) \mathrm{C}$.
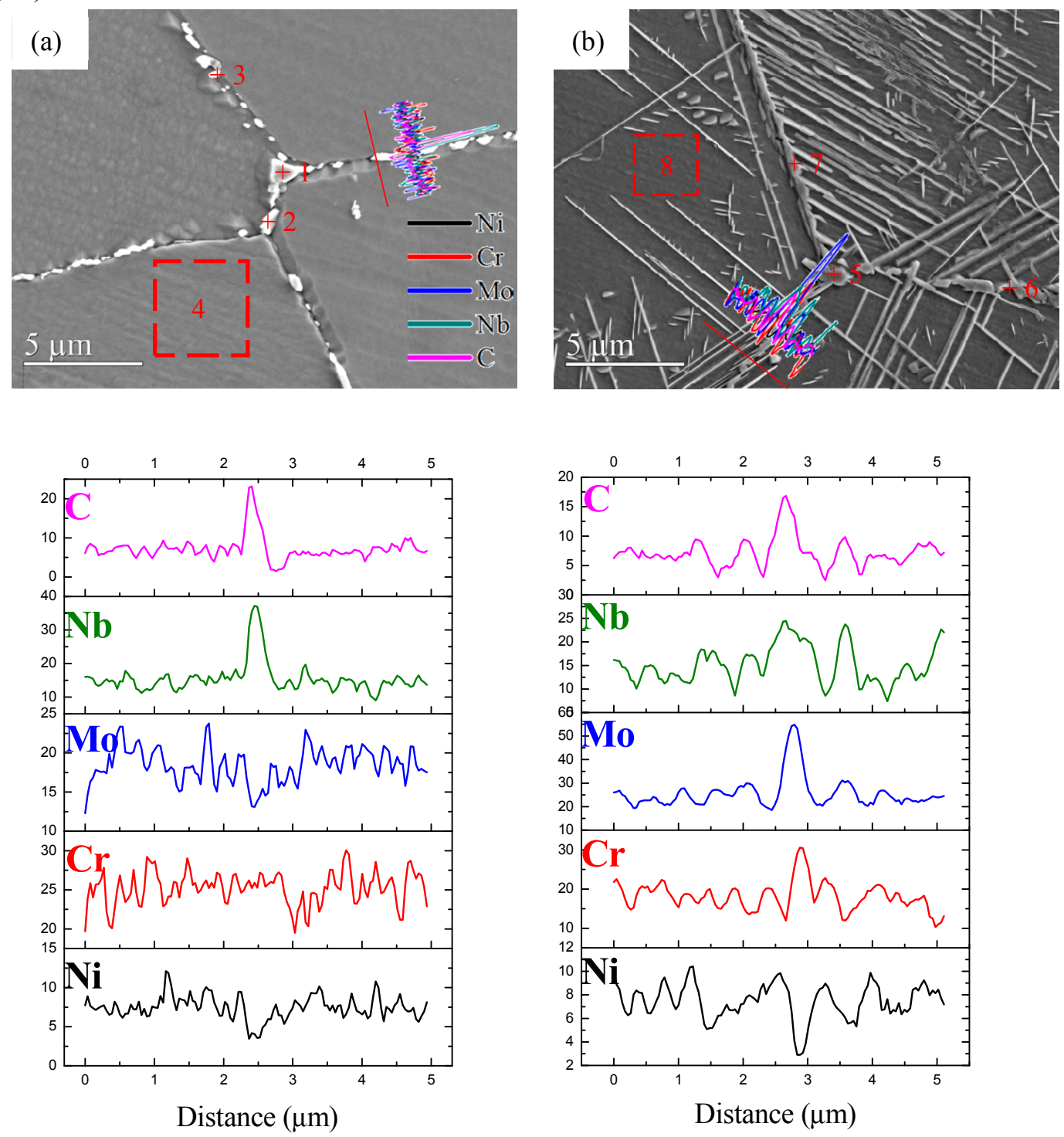

Fig.2 Microstructure of alloy by means of SEM and EDS

(a) $0 \mathrm{~h}$ aging sensitization (b) $1000 \mathrm{~h}$ aging sensitization 
Table 3. Composition at some topical points, as obtained by EDS analysis (wt $\%$ )

\begin{tabular}{ccccccc}
\hline Position & $\mathrm{Ni}$ & $\mathrm{Cr}$ & $\mathrm{Mo}$ & $\mathrm{Nb}$ & $\mathrm{Ti}$ & $\mathrm{C}$ \\
\hline P1, Fig. 2(a) & 57.03 & 13.57 & 8.33 & 11.89 & 1.70 & 7.47 \\
P2, Fig. 2(a) & 58.50 & 15.25 & 8.84 & 10.00 & 2.18 & 5.22 \\
P3, Fig. 2(a) & 55.79 & 15.75 & 13.01 & 7.60 & - & 7.85 \\
P4, Fig. 2(a) & 67.11 & 17.91 & 7.78 & 3.57 & - & 3.62 \\
P5, Fig. 2(b) & 41.42 & 39.35 & 8.83 & - & 2.31 & 8.09 \\
P6, Fig. 2(b) & 65.59 & 7.54 & 8.56 & 9.97 & 2.56 & 5.77 \\
P7, Fig. 2(b) & 41.65 & 16.00 & 30.22 & 2.42 & - & 9.71 \\
P8, Fig. 2(b) & 67.51 & 17.43 & 7.64 & 2.37 & - & 5.04 \\
\hline
\end{tabular}

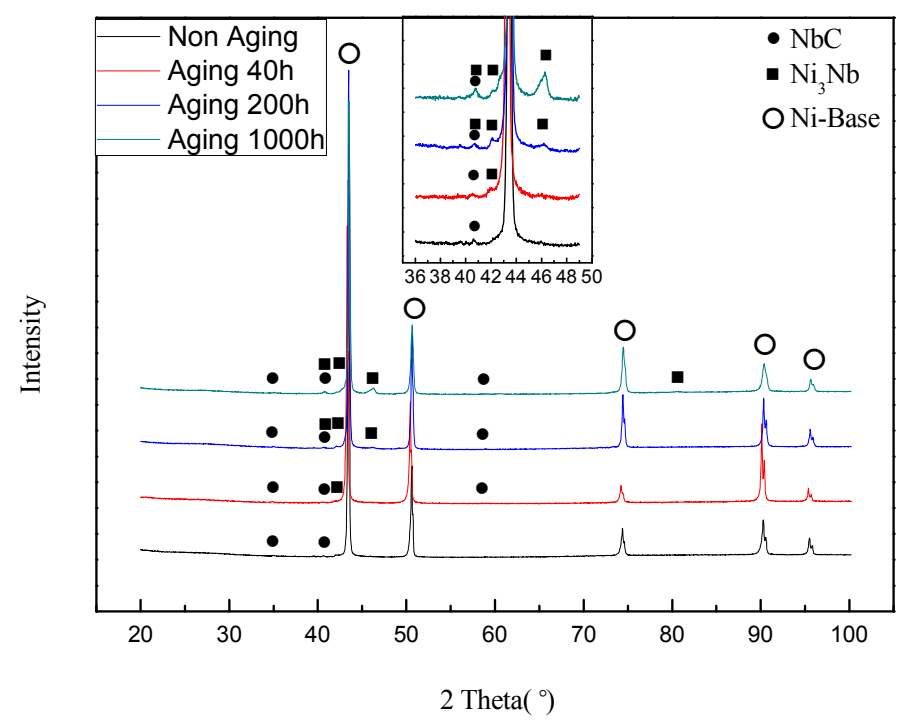

Fig 3 XRD pattern of samples with different aging time at $750^{\circ} \mathrm{C}$

Use higher multiples microscope to observe grain boundary, and analyze precipitate combined with element composition, which is measured by Energy Disperse Spectroscopy (EDS). After stabilizing treatment without aging treatment, grain boundary condition as shown in Fig 2 (a), EDS analysis shows that the discrete irregular carbides that distribute in the grain boundary are $\mathrm{Mo}, \mathrm{Nb}$ composite carbides. Granule $(\mathrm{Nb}, \mathrm{Ti}) \mathrm{C}$ exists in triple line boundary. Scanned across the grain boundary line shows that $\mathrm{C}, \mathrm{Nb}$ has enrichment in grain boundary, i.e. generate $\mathrm{NbC}$ grain and $\mathrm{Mo}, \mathrm{Cr}$ element is not found obvious enrichment. Aging treatment for $1000 \mathrm{~h}$, needle-like $\delta$ phase has a large amount of precipitation. It starts in the grain boundary with the same growth direction. Coarse $\gamma^{\prime \prime}$ phase still can be seen. Besides, the grain boundary precipitates are continuous, generates carbides with high content of $\mathrm{Cr}$ and it is distributed in triple line boundary. Meanwhile, alloy with Mo also can be discovered. Cross scanned result shows that $\mathrm{C}, \mathrm{Mo}, \mathrm{Cr}$ elements are enriched in the grain boundary. Because $\mathrm{Nb}$ element precipitate $\delta$ phase intergranular besides grain boundary carbides precipitation and it forms many peaks in scanning result. 
As shown in Fig 3 at $750^{\circ} \mathrm{C}$, XRD pattern of samples with different aging time, compared with Fig 1, precipitation $\mathrm{NbC}$ is detected in the process of stabilizing treatment. Aging treatment for 40 hours, there is tiny $\gamma^{\prime \prime}-\mathrm{Ni}{ }_{3} \mathrm{Nb}$ and generates smaller diffraction intensity. $\gamma^{\prime \prime}-\mathrm{Ni}_{3} \mathrm{Nb}$ is being precipitated gradually and degenerated into needle-like $\delta-\mathrm{Ni}_{3} \mathrm{Nb}$ by aging treatment for $200 \mathrm{~h}$. As shown in Fig, $\mathrm{Ni}_{3} \mathrm{Nb}$ diffraction intensity increases. Aging treatment for $1000 \mathrm{~h}$, there is more precipitation and precipitated phase's diffraction intensity increase further. X-ray diffraction pattern of samples with different aging time is matched with alloy's microstructure change in Fig $1,2$.

At $750^{\circ} \mathrm{C}$ aging process, compared with ferrous Alloy 625, $\gamma^{\prime \prime}$ 'phase precipitation and $\gamma^{\prime \prime} \rightarrow \delta$ phase is delayed, which have good organizational stability $[8,19,20]$. In the process of aging, the generation and evolution of $\gamma^{\prime \prime}$ phase, $\delta$ phase, precipitation in the grain boundary and alloy element in the grain boundary affects the performance of the alloy [10,21,22].

\section{2 intergranular corrosion experiment}

Alloy 625 by means of aging treatment for different time, as per ASTM G28A-02 Standard Test Methods of Detecting Susceptibility to Intergranular Corrosion in Wrought, Nickel-Rich, Chromium-Bearing Alloy Method A-Ferric Sulfate-Sulfuric Acid Test [18] requirement, it is corroded in boiled $\mathrm{H}_{2} \mathrm{SO}_{4}+\mathrm{Fe}_{2}\left(\mathrm{SO}_{4}\right)_{3}$ solution for $120 \mathrm{~h}$ and draw weightlessness curve to observe surface and cross-section feature.

$\mathrm{Fe}^{3+}$ of boiled acid $\mathrm{Fe}_{2}\left(\mathrm{SO}_{4}\right)_{3}$ solution can make the nickel substrate passivation and restrain comprehensive corrosion in $\mathrm{H}_{2} \mathrm{SO}_{4}$. Only can dissolve precipitation [23] in grain boundary element's dilution zone. The aging sensitized alloy material in this corrosion system occurs strong intergranular corrosion and causes grain fall off, generates obvious weightlessness. Weightlessness rate in different aging sensitization time is shown in Fig 4.

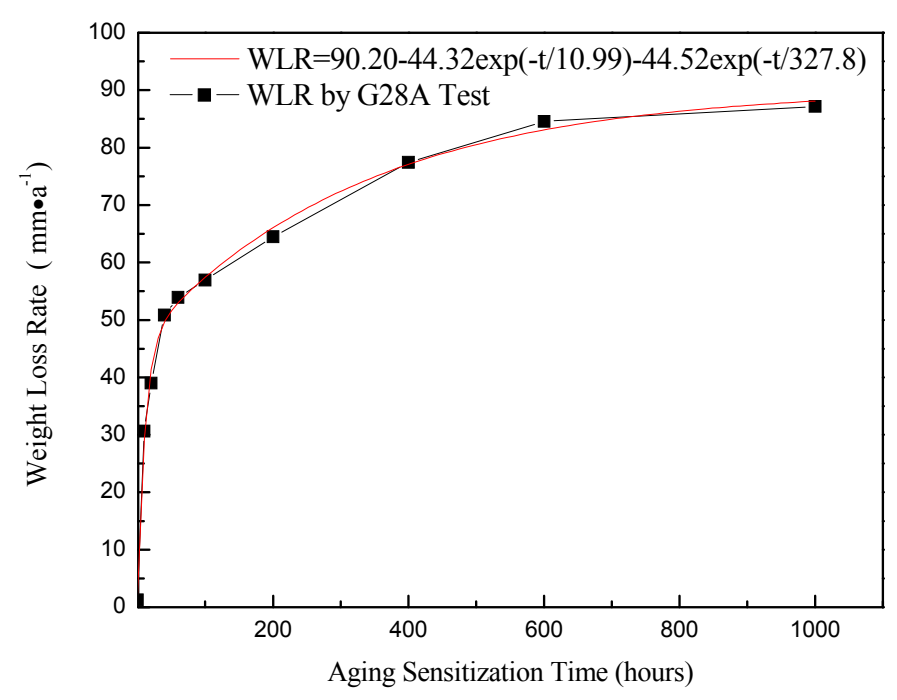

Fig 4 Alloy's weightlessness rate in different aging sensitization time 
The weightlessness rate of non-aging sensitized material is $1.267 \mathrm{~mm} / \mathrm{a}$. The corrosion morphology as shown in Fig 5 (a), at the grain boundary carbide particles dissolve, grain shape keeps intact, no obvious grain loss. Aging treatment for a short time, alloy's elements diffuse and precipitate. Alloy's intergranular corrosion sensitivity increases rapidly, weightlessness rate increases quickly, as shown in Fig 4. Aging sensitization treatment for $40 \mathrm{~h}$ to sample, weightlessness rate is about $50 \mathrm{~mm} / \mathrm{a}$. The surface appearance is shown in Fig 5 (b), grain boundary sinks as ravine and the surface grain occurs obvious fall off, which is an important reason for weightlessness rate increasing quickly. Aging sensitization treatment for $200 \mathrm{~h}$ to sample, grain keeps intact. In addition, appears few flat and straight corrosive groove. This is produced by $\delta$ phase solubility [10], as shown in Fig 5 (c), the exposed grain surface is rough with many corrosive holes, as shown in Fig 5 (e). Aging sensitization treatment for $1000 \mathrm{~h}$ to sample, not only occurs single grain fall off completely in the process of erosion. Because of lots of $\delta$ phase solubility (that run through grain), grain is divided and fall off. Exposed grain is crushed after corrosion, and the intact grain decreases, as shown in Fig 5(d). Observe crushed grain Fig 5 (f) by magnification, ice morphology is full of crossed corrosive groove. All these interlaced grooves are corresponding to $\delta$ phase form, as shown in Fig 1 (d) and 2 (b). Although the formation of $\delta$ phase changes corrosion process and corrosion morphology, but the weightlessness rate raises from $64.5 \mathrm{~mm} / \mathrm{a}$ by aging $200 \mathrm{~h}$ to $87.2 \mathrm{~mm} / \mathrm{a}$ by aging $1000 \mathrm{~h}$, as shown in Fig 4 .

As shown in Fig 6, use oxalic acid to make light corrosion for highlighting the characteristics of the cross profile, real feature of corrosion in $\mathrm{H}_{2} \mathrm{SO}_{4}+\mathrm{Fe}_{2}\left(\mathrm{SO}_{4}\right)_{3}$ doesn't loss. Stabilize samples without aging treatment, only small quantity of grain boundary is dissolved after erosion, as shown in Fig 6 (a), dissolved grain boundary generates gap. Compare with Fig 5 (a), grain boundary dissolving starts from big particle of carbides in grain boundary. It is developed internally but did not surrounded the entire grain and without falling off. With aging time prolonged, $\mathrm{Cr}$, Mo carbide is produced. $\mathrm{Cr}$ diffusion rate is low and cannot be added depleted grain boundary. Mo can be quickly spread and generate large amounts of grain boundary carbides and alloy carbide. Aging for 40h as shown in Fig 6 (b), grain fall off and cause rugged cross section of the boundary. Aging for $200 \mathrm{~h}$ and is eroded, cross section feature is shown in Fig 6 (c, e), the formation of a small amount of the $\delta$ phase causes random cross section boundary. Erode formed grain boundary space and develops internally. Meanwhile, surrounds entire grain. Then grain fall off. Analyze connect with element composition, intermittent or continuous grain boundary precipitation and near grain boundary of dilution zone is dissolved. Grain boundary space composition is similar to intergranular, but $\mathrm{Nb}$ content have significantly decrease. Aging for $1000 \mathrm{~h}$, part of the grain is completely run through a large amount of precipitated $\delta$ phase and it is dissolved in erosion process. Grain is crushed and fall off, as shown in Fig 6 (d), observe the area, as shown in Fig 6 (f), similar to Fig 5 (f), ice morphology is full of interlace corrosive groove. Due to the dissolution of the $\delta$ phase, $\mathrm{Nb}$ element in this area is not detected. Higher $\mathrm{Cr}$ element is the reason for dissolving. 

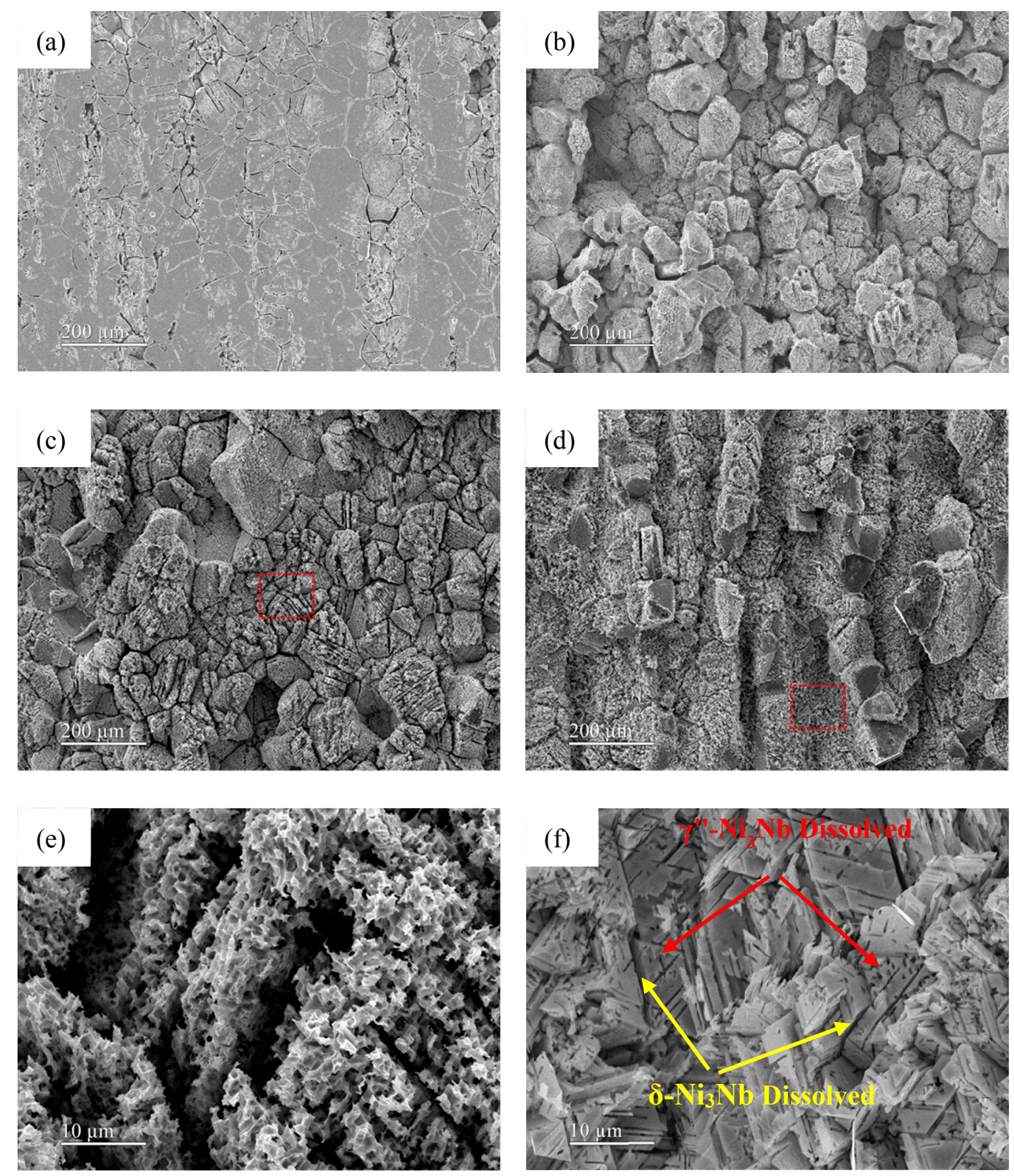

Fig.5 Surface of different aging sensitization alloy corrosion by ASTM G28A (a) $0 \mathrm{~h}$ aging sensitization (b)40h (c)200h (d)1000h

(e) High multiple of marked zone in (c) (f) High multiple of marked zone in (d) 

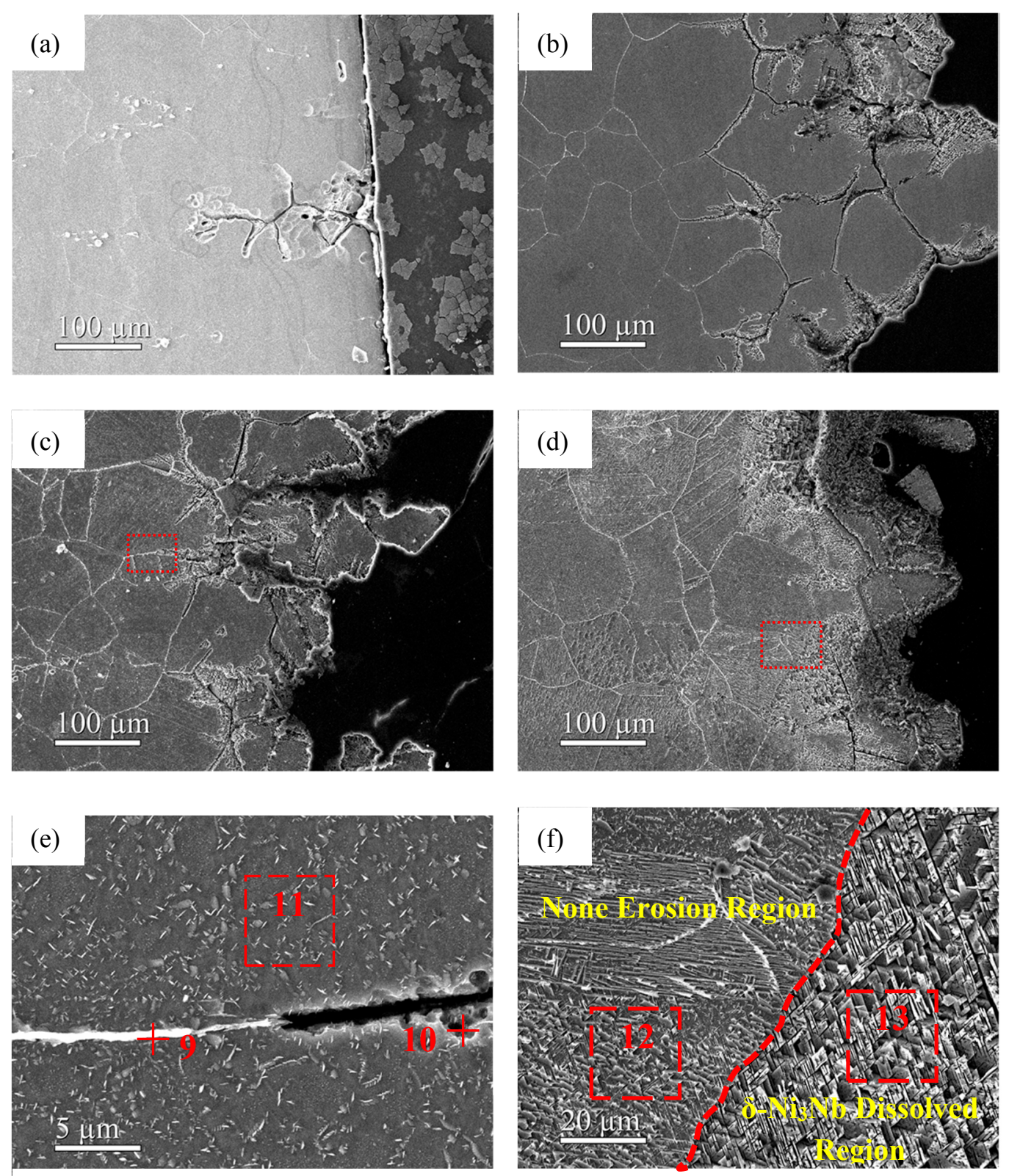

Fig.6 Section of different aging sensitization alloy corrosion by ASTM G28A

(a)0h aging sensitization (b) $40 \mathrm{~h} \mathrm{(c)200h} \mathrm{(d)100h}$

(e)Grain boundary dissolves in 200h sample marked zone in (c)

(f)Dissolves of $\delta$ phase in $1000 \mathrm{~h}$ sample marked zone in (d)

Table 4. Composition at some topical points, as obtained by EDS analysis (wt $\%$ )

\begin{tabular}{ccccccc}
\hline Position & $\mathrm{Ni}$ & $\mathrm{Cr}$ & $\mathrm{Mo}$ & $\mathrm{Nb}$ & $\mathrm{Ti}$ & $\mathrm{C}$ \\
\hline P9, Fig. 6(e) & 39.16 & 32.53 & 14.94 & 5.65 & 0.50 & 7.22 \\
P10, Fig. 6(e) & 61.62 & 23.66 & 12.25 & 0.18 & - & 2.30 \\
P11, Fig. 6(e) & 56.74 & 24.48 & 11.22 & 3.86 & - & 3.70 \\
P12 Fig. 6(f) & 64.25 & 22.48 & 8.13 & 2.19 & - & 2.95 \\
P13, Fig. 6(f) & 58.04 & 31.15 & 8.22 & - & - & 2.59 \\
\hline
\end{tabular}




\section{Discussion}

In erosion process in $\mathrm{H}_{2} \mathrm{SO}_{4}+\mathrm{Fe}_{2}\left(\mathrm{SO}_{4}\right)_{3}$ solution, $\mathrm{Fe}^{3+}$ can prevent alloy's complete corrosion in $\mathrm{H}_{2} \mathrm{SO}_{4}$. Only erode dilution zone of grain boundary. Aging sensitized sample occurs strong intergranular corrosion and grain fall off in solution. Intergranular corrosion sensitivity can be evaluated by weightlessness method.

At $750^{\circ} \mathrm{C}$ aging sensitization process, $\mathrm{Cr}$, Mo separates from the grain boundary of the solid solution. Its carbide and alloy phase precipitates along the grain boundary, which makes the continuous distribution of grain boundary precipitates. Due to the Cr's diffusion rate is far lower than C, Cr can't diffuse timely from solution and add to grain boundary. Therefore, has to consume $\mathrm{Cr}$ nearby grain boundary. This causes poor $\mathrm{Cr}$ area of grain boundary [13]. Cr content value of poor $\mathrm{Cr}$ area is far below the limit value of passivation needed, its potential is lower than grain's internal potential, much lower than the precipitated phase of grain boundary. Poor $\mathrm{Cr}$ area connects closely with precipitated phase of grain boundary. Short circuit cell effect occurs when come across with corrosive medium and poor $\mathrm{Cr}$ area is eroded rapidly [23,24].

Use Fick's second law to calculate width and precipitated amount of alloy element in dilution zone:

$$
\frac{\partial \mathrm{C}}{\partial \mathrm{t}}=D \frac{\partial^{2} \mathrm{C}}{\partial x^{2}}
$$

Determine the initial and boundary conditions:

$$
\begin{aligned}
& \mathrm{t}=0 \text { 时, }\left\{\begin{array}{l}
C=C_{P}, x=0 \\
C=C_{G}^{0}, x>0 ;
\end{array}\right. \\
& \mathrm{t}>0 \text { 时, }\left\{\begin{array}{c}
C=C_{P}, x=0 \\
C=C_{G}^{0}, x=+\infty
\end{array}\right. \text {. }
\end{aligned}
$$

Use Boltzmann transform and Gauss error function, get the result:

$$
\begin{gathered}
\mathrm{C}(\mathrm{x}, \mathrm{t})=C_{P}+\left(C_{G}^{0}-C_{P}\right) \cdot \frac{2}{\sqrt{\pi}} \int_{0}^{\beta} \exp \left(-\beta^{2}\right) d \beta,\left(\beta=\frac{x}{2 \sqrt{D t}}\right) \\
\text { 即: } \mathrm{C}(\mathrm{x}, \mathrm{t})=C_{P}+\left(C_{G}^{0}-C_{P}\right) \operatorname{erf}\left(\frac{x}{2 \sqrt{D t}}\right)
\end{gathered}
$$

Among them: $C_{P^{-}}$precipitation phase of grain boundary and alloy element concentration of substrate's interface; non-sensitized alloy's concentration of $C_{G^{-}}^{0}$ interior part; $x$-distance to grain boundary; D- alloy element diffusion coefficient; $t$ sensitization time.

Alloy element of grain boundary precipitation by different sensitization time causes dilution zone's composition change, qualitative results are shown in Fig 7, among them, dilution zone width of non- generation of the passivation film after different aging sensitization time: $x_{40}=\frac{x_{200}}{\sqrt{5}}=\frac{x_{1000}}{5}$, which is in direct proportion to the square root of the sensitization time, i.e. the dilution zone volume obeys the rule of parabola. 


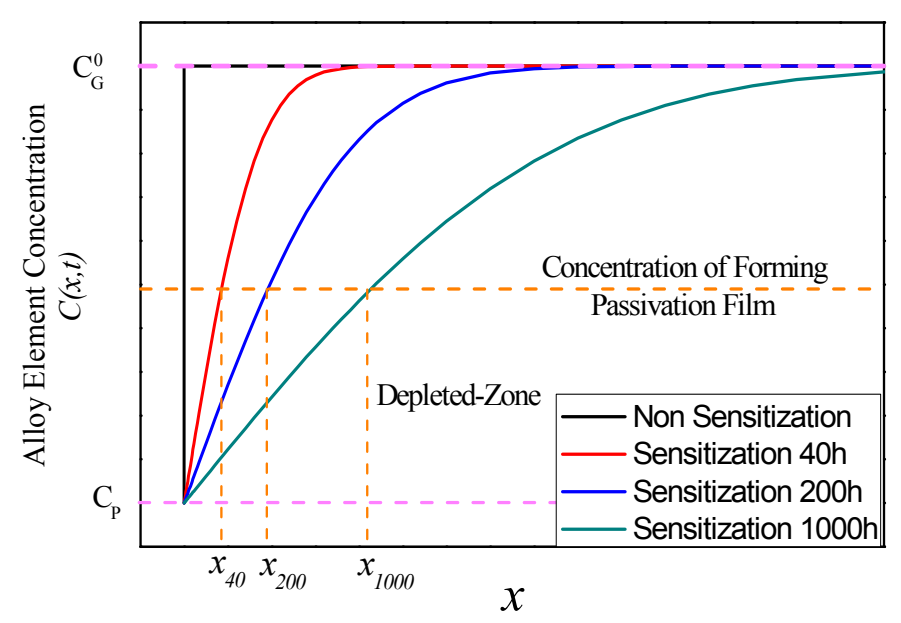

Fig 7 Grain boundary alloy element's dilution zone content change by different sensitization time

As can be seen from the Fig $5 \sim 6$, with the extension of aging time, the grain boundary space formed by the corrosion begins in surface carbide or alloy phase. It grows internally and surrounds the entire grain, which makes the grain fall off. This belongs to the typical intergranular corrosion. In addition, as the extension of sensitization time, precipitated phase forms and $\gamma^{\prime \prime}$ phase that exposed to the corrosive medium is eroded but doesn't develop to the grain interior. $\delta$ phase is dissolved because can't form passivation film and presents the glacier surface. Carbide precipitated in grain boundary and intermetallic in the corrosion process are also dissolved because electric potential is lower than the grain interior pare, as shown in Fig 8.

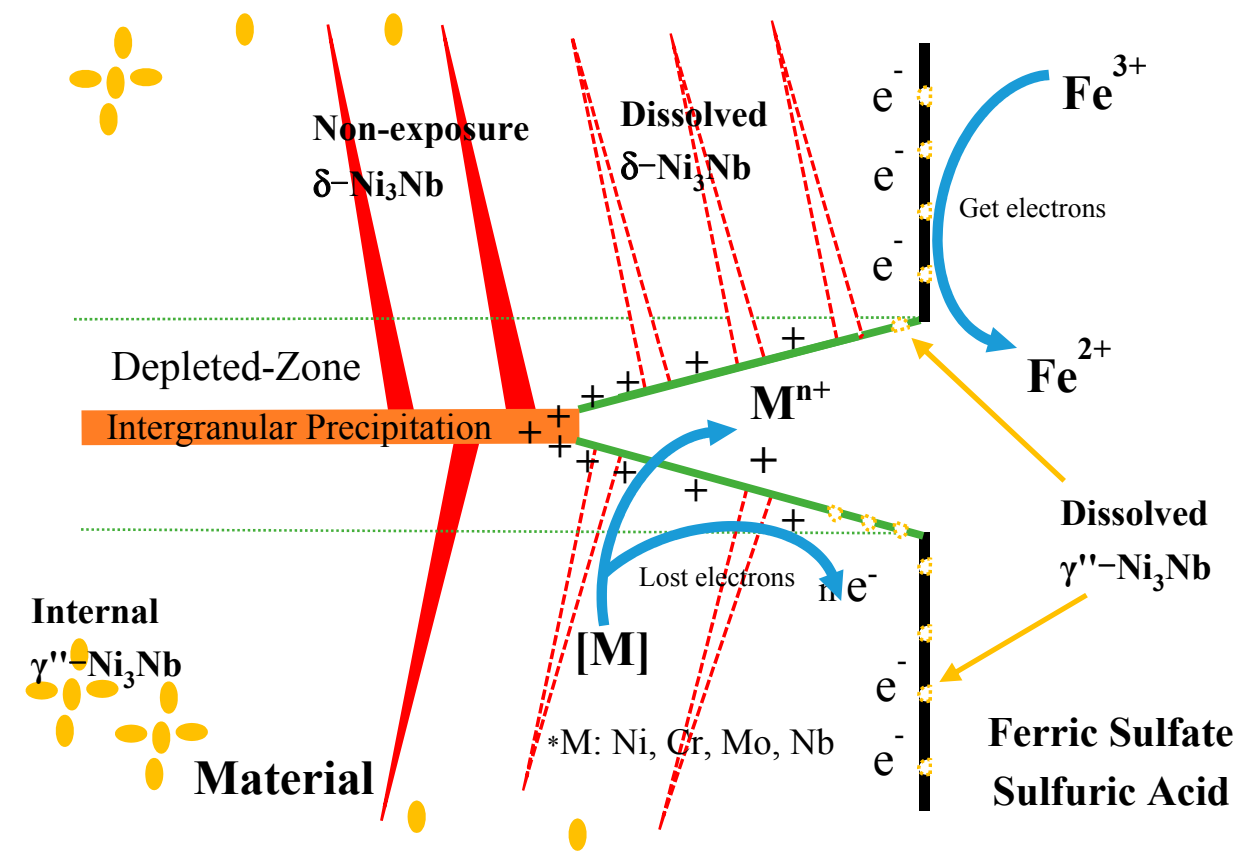

Fig 8 Dissolving Fig of erosion process

Above all, erosion sample weight loss rate (WLR), i.e. poor $\mathrm{Cr}$ area and precipitate phase dissolving of grain boundary causes grain fall off [23]. Its formation is related 
with alloy element diffusion [13]. With the extension of aging time, after aging for 200h, needle-like $\delta$ phase generates which can't form passivation film [10]. It will make the grain crush and spall, WLR rises further. However, in the acidic ferric sulfate erosion experiments, WLR is not direct proportional to the square root of the sensitization time. Especially within $200 \mathrm{~h}$, no needle-like $\delta$ phase affect, i.e. WLR can't only be explained by diffusion theory. Considering the gravity erosion mainly is grain fall off. when the grain boundary is completely dissolved, the grain falls off, including $\delta$ phase, grain boundary precipitation, elements' dilution zone. Elements' dilution area is associated with and accompanies grain boundary precipitation formation, which can be considered as an item. Erosion weightlessness should be proportional to the number of precipitated phase. Precipitated phase nucleation grows big can represented by Johnson-MehlAvrami(JMA) equations [25]. This can further get relationship between erosion WLR and aging sensitization time. JMA equation [26-28]:

$$
f=1-\exp \left(-k t^{n}\right)
$$

Among them: f-precipitated phase relative volume fraction: $t$ - time and infinite long exhalation phase volume ratio; $\mathrm{k}$ - independent constant related to the temperature; $\mathrm{n}$ - the power exponent of time, the independent constant from 1 4.

Take element dilution zone which is non-passivation film and its formed the grain boundary precipitated phase as one independent phase, due their formation is related and linked with each other, can get:

$$
\left\{\begin{array}{c}
f_{i p}=1-\exp \left(-k_{i p} t^{n_{1}}\right) \\
f_{\delta}=1-\exp \left(-k_{\delta} t^{n_{2}}\right)
\end{array}\right.
$$

Among them: $f_{i p}$ - precipitated phase and grain boundary element dilution zone relative volume fraction; $f_{\delta}$ - needle-like $\delta$ phase relative volume fraction.

In addition, erosion weightlessness rate:

$$
W L R=a f_{i p}+b f_{\delta}+c(m m / a)
$$

Among them: a, b, c - the weights of WLR, erosion WLR constant;

$\mathrm{t}=0$, no sensitization processing sample $W L R=c=1.267(\mathrm{~mm} / \mathrm{a})$

Takes formula (4) (5), calculated WLR with sensitized sample, as shown in Fig 4:

$$
W L R=44.32\left[1-\exp \left(-\frac{t}{10.99}\right)\right]+44.62\left[1-\exp \left(-\frac{t}{327.8}\right)\right]+1.267(\mathrm{~mm} / \mathrm{a})
$$

$$
a=44.32, b=44.62, k_{i p}=\frac{1}{10.99}, k_{\delta}=\frac{1}{327.8}, n_{1}=1, n_{2}=1 \text {. }
$$

It is visible that WLR weight values a is similar to $b$. Precipitate phase of dilution zone and needle-like phase dissolving makes similar contribution to erosion weightlessness. In addition, by :

$$
\exp (-0.7)=0.5
$$

Can get a $50 \%$ shift time $t_{0.5, \mathrm{ip}}=7.693 \mathrm{~h}, t_{0.5, \delta}=229.5 \mathrm{~h}$. Because a small amount of precipitated phase can cause the obvious change of the corrosion process, lead to fast grain spalling. Use precipitated phase to erosion weightlessness affect to 
represent precipitation. This increased precipitation rate excessively. Precipitated phase at this time is far from 50\%. However, dilution zone and intergranular precipitate phase forms in the early aging stage. Needle-like $\delta$ phase precipitates at about $200 \mathrm{~h}$, which is matched with Fig 1, 6 .

Using ASTM G28A Ferric Sulfate-Sulfuric Acid Test measurement 'can reflect the experiment used materials' intergranular corrosion property change with aging sensitization treatment time. Because precipitated phase and dilution zone in the process of erosion cause grain spalling, which can be explained by precipitation phase transformation volume fraction.

\section{Conclusion}

Sample alloy that is stable after solid solution, observe its structure change by different aging sensitization treatment at $750^{\circ} \mathrm{C}$, using ASTM G28A - Ferric SulfateSulfuric Acid Test to represent alloy's anti-intergranular corrosion change in aging sensitization process, and analyze and establish weightlessness model of intergranular corrosion, then get the low conclusions:

1) Use $X R D$ and SEM to determine interior alloy aging precipitation behavior: precipitates small $\gamma^{\prime \prime}-\mathrm{Ni} 3 \mathrm{Nb}$ by aging $40 \mathrm{~h}$ at $750^{\circ} \mathrm{C}$, generate transformation of $\gamma^{\prime \prime} \rightarrow \delta$ $\mathrm{Ni}_{3} \mathrm{Nb}$ by aging for $200 \mathrm{~h}$. By extension of long aging treatment, needle-like $\delta-\mathrm{Ni}{ }_{3} \mathrm{Nb}$ increases. In aging process, grain boundary carbides and intermetallic compound forms alloy elements dilution zone.

2) ASTM G28A erosion result shows that samples without aging sensitization treatment, only carbides of grain boundary dissolves. Its WLR is $1.267 \mathrm{~mm} / \mathrm{a}$ with good corrosion resistance. In early aging sensitization, in grain boundary elements $(\mathrm{Cr}, \mathrm{Mo})$ dilution zone, intergranular precipitates dissolves, grain falls off and sample WLR increases rapidly. With formation and precipitation of needle-like $\delta$-Ni3 $\mathrm{Nb}$ phase that unable to form passivation film, grain crushes and spalls. Present a glacial topography in surface and alloy samples WLR raises further.

3) Element dilution zone and precipitated phase dissolving causes quickly fall off of grain. Curve of ASTM G28A erosion WLR changes with aging sensitization time can be explained by precipitation phase transformation volume fraction Johnson-MehlAvrami equation: erosion WLR: $\quad W L R=44.32\left[1-\exp \left(-\frac{t}{10.99}\right)\right]+44.62[1-$ $\left.\exp \left(-\frac{t}{327.8}\right)\right]+1.267(m m / a)$

\section{Acknowledgments}

The authors gratefully appreciate the financial support of Science and Technology Program of Jiangsu Province (Nos. BE2015144 and BE2015145) and the partner company, Jiangsu XINHUA Alloy Electric CO., LTD.. 


\section{References}

[1] S.A. Al-Fozan, A.U. Malik, Effect of seawater level on corrosion behavior of different alloys, Desalination. 228 (2008) 61-67. doi:10.1016/j.desal.2007.08.007.

[2] Z.F. Yin, W.Z. Zhao, W.Y. Lai, X.H. Zhao, Electrochemical behaviour of Ni-base alloys exposed under oil/gas field environments, Corrosion Science. 51 (2009) 1702-1706. doi:10.1016/j.corsci.2009.04.019.

[3] B.D. Esser, N. Antolin, A. Carlsson, R.E.A. Williams, A. Wessman, T. Hanlon, et al., Phase transformation strengthening of high-temperature superalloys, Nature Communications. 7 (2016) 1-7. doi:10.1038/ncomms13434.

[4] R.S. Dutta, Corrosion aspects of $\mathrm{Ni}-\mathrm{Cr}-\mathrm{Fe}$ based and $\mathrm{Ni}-\mathrm{Cu}$ based steam generator tube materials, Journal of Nuclear Materials. 393 (2009) 343-349. doi:10.1016/j.jnucmat.2009.06.020.

[5] K.S.A.T.R.A. X Ren, Corrosion Behavior of Alloys 625 and 718 in Supercritical Water, (2007) $1-1$.

[6] V. Shankar, K. Bhanu Sankara Rao, S.L. Mannan, Microstructure and mechanical properties of Inconel 625 superalloy, Journal of Nuclear Materials. 288 (2001) 222-232. doi:10.1016/S0022-3115(00)00723-6.

[7] L.M. Suave, D. Bertheau, J. Cormier, P. Villechaise, A. Soula, Z. Hervier, et al., Impact of Thermomechanical Aging on Alloy 625 High Temperature Mechanical Properties, in: 8th International Symposium on Superalloy 718 and Derivatives, John Wiley \& Sons, Inc, Hoboken, NJ, USA, 2014: pp. 317-331. doi:10.1002/9781119016854.ch26.

[8] L.M. Suave, J. Cormier, P. Villechaise, A. Soula, Z. Hervier, D. Bertheau, et al., Microstructural Evolutions During Thermal Aging of Alloy 625: Impact of Temperature and Forming Process, Metall and Mat Trans A. 45 (2014) 2963-2982. doi:10.1007/s11661-0142256-7.

[9] M.A. Shaikh, M. Ahmad, K.A. Shoaib, J.I. Akhter, M. Iqbal, Precipitation hardening in Inconel *625, Materials Science and Technology. 16 (2013) 129-132. doi:10.1179/026708300101507613.

[10] H.M. Tawancy, I.M. Allam, N.M. Abbas, Effect of Ni3Nb precipitation on the corrosion resistance of Inconel alloy 625, J Mater Sci Lett. 9 (1990) 343-347. doi:10.1007/BF00725845.

[11] K. Kaneko, T. Fukunaga, K. Yamada, N. Nakada, M. Kikuchi, Z. Saghi, et al., Formation of M23C6-type precipitates and chromium-depleted zones in austenite stainless steel, Scripta Materialia. 65 (2011) 509-512. doi:10.1016/j.scriptamat.2011.06.010.

[12] Y.M. Pan, D.S. Dunn, G.A. Cragnolino, N. Sridhar, Grain-boundary chemistry and intergranular corrosion in alloy 825, Metall and Mat Trans A. 31 (2003) 1163-1173. doi:10.1007/s11661-000-0112-4.

[13] H. Sahlaoui, H. Sidhom, J. Philibert, Prediction of chromium depleted-zone evolution during aging of Ni-Cr-Fe alloys, Acta Materialia. 50 (2002) 1383-1392.

[14] S.K. B, B.S. Prasad, V. Kain, J. Reddy, Methods for making alloy 600 resistant to sensitization and intergranular corrosion, Corrosion Science. $70 \quad$ (2013) 55-61. doi:10.1016/j.corsci.2012.12.021.

[15] K. ke-hsin, Phases in high alloy steels and superalloys, Acta Metallurgica Sinica. 14 (1978) 73-95. http://www.cnki.com.cn/Article/CJFDTotal-JSXB197801008.htm.

[16] L. Yuan, R. Hu, T. Zhang, Y. Han, X. Xue, J. Li, Precipitation Behavior of $\sigma-F e C r$ Phases in Hastelloy C-2000 Superalloy Under Plastic Deformation and Aging Treatment, J. of Materi Eng and Perform. 24 (2014) 565-571. doi:10.1007/s11665-014-1351-7.

[17] C.M. Kuo, Y.T. Yang, H.Y. Bor, C.N. Wei, C.C. Tai, Aging effects on the microstructure and creep behavior of Inconel 718 superalloy, Materials Science and Engineering: A. 510-511 (2009) 289-294. doi:10.1016/j.msea.2008.04.097.

[18] Standard Test Methods for Detecting Susceptibility to Intergranular Corrosion in Wrought, Nickel-Rich, Chromium-Bearing Alloys, Astm. (2008).

[19] N.D. Evans, P.J. Maziasz, J.P. Shingledecker, Y. Yamamoto, Microstructure evolution of alloy 625 foil and sheet during creep at $750^{\circ} \mathrm{C}$, Materials Science and Engineering: A. 498 (2008) 412-420. doi:10.1016/j.msea.2008.08.017.

[20] I.J. Moore, J.I. Taylor, M.W. Tracy, M.G. Burke, E.J. Palmiere, Grain coarsening behaviour of solution annealed Alloy 625 between $600-800^{\circ} \mathrm{C}$, Materials Science and Engineering: A. 682 (2017) 402-409. doi:10.1016/j.msea.2016.11.060. 
[21] J.J. Kai, G.P. Yu, C.H. Tsai, M.N. Liu, S.C. Yao, The effects of heat treatment on the chromium depletion, precipitate evolution, and corrosion resistance of INCONEL alloy 690, Mta. 20 (2007) 2057-2067. doi:10.1007/BF02650292.

[22] M. Kamrunnahar, M. Urquidi-Macdonald, Prediction of corrosion behavior using neural network as a data mining tool, Corrosion Science. 52 (2010) 669-677. doi:10.1016/j.corsci.2009.10.024.

[23] M. Prohaska, H. Kanduth, G. Mori, R. Grill, G. Tischler, On the substitution of conventional corrosion tests by an electrochemical potentiokinetic reactivation test, Corrosion Science. 52 (2010) 1582-1592. doi:10.1016/j.corsci.2010.01.017.

[24] X.-J. Di, X.-Q. Liu, C.-X. Chen, B.-S. Wang, X.-J. Guo, Effect of Post-weld Heat Treatment on the Microstructure and Corrosion Resistance of Deposited Metal of a High- Chromium Nickel-Based Alloy, Acta Metallurgica Sinica (English Letters). 29 (2016) 1136-1143. doi:10.1007/s40195-016-0504-0.

[25] J.J. Jonas, X. Quelennec, L. Jiang, É. Martin, The Avrami kinetics of dynamic recrystallization, Acta Materialia. 57 (2009) 2748-2756. doi:10.1016/j.actamat.2009.02.033.

[26] M. Avrami, Kinetics of Phase Change. I General Theory, Journal of Chemical Physics. 7 (1939) 1103-1112.

[27] M. Avrami, Kinetics of Phase Change 2, Journal of Chemical Physics. 7 (1939) 1103-1112.

[28] W.A. Johnson, R.F. Mehl, Reaction Kinetics in Process of Nucleation and Growth, Journal of Chemical Physics. 8 (1940) 212-1112. doi:10.1063/1.1750380. 